DOI: $10.17516 / 1997-1370-0883$

УДК 782.1

\title{
The Image of Parfen Rogozhin in «The Idiot», the Opera by M. Weinberg and A. Medvedev
}

\author{
Svetlana G. Voitkevich* and Vera P. Baranova \\ Dmitri Hvorostovsky Siberian State Academy of Arts \\ Krasnoyarsk, Russian Federation
}

Received 10.10.2021, received in revised form 10.12.2021, accepted 18.01.2022

\begin{abstract}
The article is to commemorate the $200^{\text {th }}$ anniversary of Fedor Mikhailovich Dostoyevsky; it concerns a musical version of his novel, «The Idiot». The Russian writer's work has attracted attention of many composers. In 1986 Mieczysław Weinberg completed the eponymous opera. The librettist Aleksandr Medvedev follows the logic of the original story and constructs the musical drama preserving the specific features and versatility of each character, which is also reflected in the music. The image of Parfen Rogozhin reveals the development of his contradictory nature. The character is represented with ensemble and solo scenes. Parfen's Song from Scene Nine stands out among the solos. The song "Akh, talan li moi, talan» (Oh My Bad Luck) is quoted as its source. The lyrics of the song were first published together with its tune in 1790, in a book edited by N.A. Lvov and I. G. Prach, «Collection of Russian Folk Songs with Their Tunes» (Lvov-Prach Collection). The study has found that there are different versions of the text in the oral tradition. Their variety can be reduced to two types: the bridal song and the jailhouse ballad with its steady archetype of «beauty and the rogue». Each type has a semantic correlation in the context of the opera. The quotation obviously changes in the opera. The librettist has introduced his own lines enhancing the tragic focus of the song. The composer renders them in the tune emphasizing the intonation intrinsic to the genre of lamentation.
\end{abstract}

Keywords: F. M. Dostoyevsky, M. S. Weinberg, A. V. Medvedev; The Idiot, a novel; contemporary opera, folklore, quotation, song.

Research area: musical art.

Citation: Voitkevich, S.G., Baranova, V.P. (2022). The image of Parfen Rogozhin in «The Idiot», the opera by M. Weinberg and A. Medvedev. J. Sib. Fed. Univ. Humanit. soc. sci., 15(1), 133-140. DOI: 10.17516/1997$1370-0883$

(C) Siberian Federal University. All rights reserved

* Corresponding author E-mail address: tr@kgii.ru 


\title{
Образ Парфена Рогожина в опере М. Вайнберга и А. Медведева «Идиот»
}

\author{
С.Г. Войткевич, В.П. Баранова \\ Сибирский государственный институт искусств \\ имени Дмитрия Хворостовского \\ Российская Федерачия, Красноярск
}

\begin{abstract}
Аннотация. Статья приурочена к 200-летнему юбилею Федора Михайловича Достоевского и посвящена одному из музыкальных прочтений романа «Идиот». Это сочинение русского писателя чаще других привлекало внимание композиторов. В 1986 году Мечислав Вайнберг завершил оперу с одноименным названием. Либреттист Александр Медведев следует логике литературного первоисточника и выстраивает музыкальную драму, сохраняя специфику и многогранность каждого образа. Это находит отражение в музыке. Развитие образа Парфена Рогожина демонстрирует противоречия персонажа. Он представлен ансамблевыми и сольными сценами. Среди последних особенно выделяется Песня Парфена, которая звучит в девятой картине. В ее основу положена цитата песни «Ах, талан ли мой, талан». Впервые текст песни вместе с напевом был опубликован в 1790 году в сборнике Н. А. Львова и И.Г. Прача «Собрание народных русских песен с их голосами». Исследование показало, что данный текст бытует в устной традиции в разных вариантах. Их многообразие можно свести к двум типам: свадебная песня и балладная песня тюремного характера с устойчивым архетипом «красавица и разбойник». В контексте оперы каждый из типов находит свой смысловой коррелят. Цитата претерпевает в опере очевидные изменения. Либреттист привносит собственные строки, усиливающие трагическую направленность. Композитор передает их в напеве, акцентируя интонацию, свойственную жанру причитаний.
\end{abstract}

Ключевые слова: Ф.М. Достоевский, М.С. Вайнберг, А. В. Медведев, роман «Идиот», современная опера, фольклор, цитата, песня.

Специальность 17.00.02 - музыкальное искусство.

\section{Введение}

В 2021 году отмечалось 200-летие со дня рождения великого русского писателя Федора Михайловича Достоевского. Его наследие до сих пор привлекает ученых всего мира, подтверждением чему является большое количество исследований, посвященных творчеству автора «Братьев Карамазовых», a также регулярно проводимые научные мероприятия, где озвучиваются результаты новейших изысканий. Институт русской литературы (Пушкинский Дом) Российской академии наук начал публикацию нового академического издания «Полное собрание сочинений и писем Ф.М. Достоевского», которое выйдет в 35 томах.
Юбилей Достоевского нашел отражение в репертуаре драматических и оперных театров. В канун празднований два ведущих оперных театра страны представили зрителю различные версии опер М. Вайнберга и А. Смелкова на сюжет одного из самых популярных романов писателя - «ИдиOT».

Если взглянуть на историю оперной достоевистики, начатой в 1916 году оперой Сергея Прокофьева «Игрок», то окажется, что самое большое количество сценических воплощений на музыкальной сцене принадлежит сюжету о «положительно прекрасном человеке» - князе Льве Николаевиче Мышкине. Первая попытка написать оперу 
на этот сюжет принадлежит Николаю Яковлевичу Мясковскому. С 1908 по 1918 год он работал над оперой «Идиот». Сочинение осталось незавершенным. Обратим внимание на то, что роман Достоевского был единственным сюжетом, который «увлек Мясковского надолго и по-настоящему» (Lobanova, 2016: 127).

Спустя несколько десятилетий историю о Князе Христе воплотил в музыке немецкий автор Ханс Вернер Хенце, создавший в 1952 году балет-пантомиму «Идиот» (камерный балет). Десятью годами позже чех Карел Купка написал сначала балет (1962), а затем оперу «Идиот» (1964). Первая русская завершенная оперная версия принадлежит Валериану Михайловичу Богданову-Березовскому, который назвал свое сочинение «Настасья Филипповна» (1964). В последующие годы возникли оперы «Идиот» Лучано Шайя (Лучиано Чайли) (обе 1970), «Князь Мышкин» Александра Балтина (1983), «Идиот» Мечислава Вайнберга (1986), камерная опера Владимира Кобекина «Н.Ф.Б.» (1995); телеопера Джона Чарльза Итона «Мышкин» (1973), рокопера Александра Ковалева (2015). Сюжет романа Достоевского оказался привлекательным для балетмейстеров, свидетельством чему являются постановки Валерия Панова (1979, на музыку Дмитрия Дми- триевича Шостаковича), Бориса Эйфмана (1980, на музыку Шестой симфонии Петра Ильича Чайковского), Надежды Калининой (2015, на музыку «Манфреда», Шестой симфонии, Первой и Третьей сюит Петра Ильича Чайковского). Неоднозначные отклики в прессе вызвал драматический спектакль с балетными интермедиями Режиса Обадиа, представленный на сцене РАМТ (2004). Последним сочинением стала опера санктпетербургского композитора Александра Смелкова. Ее мировая премьера (концертное исполнение) состоялась 22 и 24 января 2021 года на Приморской сцене Мариинского театра.

\section{Постановка проблемы}

В ряду названных произведений особо выделяется опера Мечислава Самуиловича Вайнберга «Идиот» (рис. 1), написанная в 1986 году на либретто Александра Викторовича Медведева и ожидавшая премьеры первой авторской редакции долгих 30 лет. В 2016 году Государственный академический Большой театр в Москве и Мариинский театр в Санкт-Петербурге осуществили постановку оперы, и спектакль стал репертуарным.

Переводя сложный мир прозы писателя на музыкальный язык, Медведев и Вайнберг сохранили многие константы

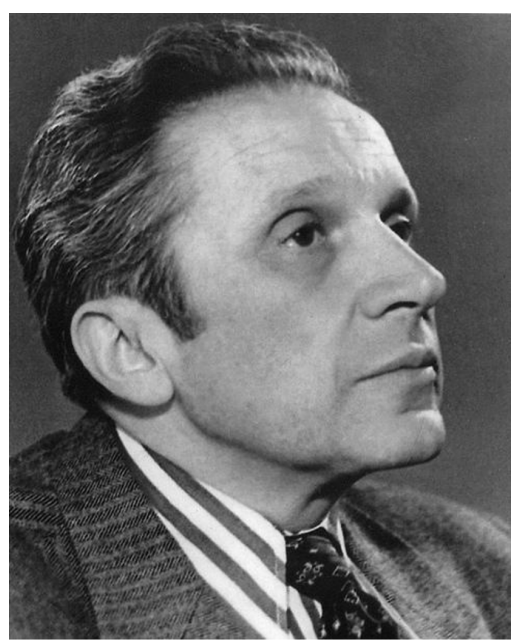

Рис. 1. Мечислав Вайнберг (1919-1996)

Fig. 1. Mechislav Weinberg (1919-1996) 
литературного первоисточника. Центральным персонажем оперы стал Лев Николаевич Мышкин. В либретто используется не только текст романа, но и другие источники. Это стихотворные строки Якова Полонского и Николая Языкова, эпистолярий Федора Михайловича Достоевского. Кроме того, встречаются «передача реплик одних персонажей другим, принцип монтажности на текстовом и драматургическом уровнях, столкновение идей, персонифицированных в героях оперы» (Voitkevich, 2020: 995). В большинстве случаев введение «чужого слова» служит цели представить заглавного героя как «положительно прекрасного человека». И только один раз в опере появляется цитата, связанная с образом Рогожина. Предпримем попытку обосновать причины обращения авторов оперного «Идиота» к теме подлинной русской песни.

\section{Обсуждение}

Либреттист оперы Александр Медведев следовал логике литературного первоисточника. Поэтому Парфен Рогожин появляется в первой сцене оперы, где происходит знакомство «последнего из рода князей Мышкиных» и «сына потомственного почетного гражданина Семена Парфеновича Рогожина». Купеческий сын рассказывает о событиях, произошедших «чрез Настасью Филипповну» (Dostoevskij, 1973: 8). Поначалу он представлен как разгульный грубоватый персонаж. Парфен не скрывает своей необразованности: «У нас, у родителя, попробуй-ка, в балет сходить, - одна расправа, убьет!» (Dostoevskij, 1973: 12). При том, что старший Рогожин богат, сын ходит «в третьегодняшней отцовской бекеше» ${ }^{1}$, «в смазных сапогах»². В разговоре Гани Ивол-

\footnotetext{
1 Бекеша - верхняя мужская одежда, пальто с длинными полами сюртучного типа. Отличительной чертой являлся отрезной по талии крой.

2 Сапоги, сшитые кожей вовнутрь. Пропитывались салом или дегтем, благодаря чему служили долго. В данном случае смазные сапоги и бекеша с отцовского плеча свидетельствуют о скупости Семена Парфеновича, который при своем достатке экономил на сыновьях, не считая возможным покупать им персональную одежду или личные сапоги - менее ноские, но зато имевшие более презентабельный вид.
}

гина и генерала Епанчина, которые обсуждают Рогожина, звучит пренебрежительное «купеческий сынок», «купчик». На первых страницах романа писатель называет героя «черномазый», а затем нередко использует слово «грязный» при характеристике Парфена: он является на день рождения к Настасье Филипповне в грязных сапожищах, с массивным бриллиантовым перстнем «на грязном пальце правой руки» (Dostoevskij, 1973: 135), с деньгами в «грязной пачке» (Dostoevskij, 1973: 136). Решив разыскать дом Рогожина, Князь сразу же угадывает его по «физиономии»: «Дом этот был большой, мрачный, в три этажа, без всякой архитектуры, цвету грязно-зеленого» (Dostoevskij, 1973: 170).

Тем очевиднее перемены, происходящие с Парфеном. В начале второй части романа Мышкин говорит товарищу: «... всю компанию разогнал; сам вот в родительском доме сидишь, не проказишь» (Dostoevskij, 1973: 172). Купеческий наследник читает книги по реестру, составленному Настасьей Филипповной, и среди них «История России с древнейших времен» Сергея Михайловича Соловьева, первый том которой был опубликован в 1851 году. В третьей части романа читатель узнает, что поражавший и пугавший окружающих своими безобразными кутежами и пьянством Рогожин, придя на дачу с Мышкиным, «во весь вечер не выпил ни одной капли вина» (Dostoevskij, 1973: 316).

Линия образа, очерченная в романе, находит отражение и в опере. Так, в сцене Парфена с ростовщиками, возникающей «наплывом» во второй картине («У Епанчиных»), во время появления Парфена в доме Иволгиных (картина третья «У Иволгиных»), а затем у Настасьи Филипповны (четвертая картина «День ангела») в оркестровой партии возникают ритмы и интонации, характерные для жанра пляса. Форшлаги медных духовых, синкопированные «перебивы», гемиоли, переменный метр передают разухабистый и наглый характер пьяного «купчика», не знающего удержу и потрясающего мошной. Однако в эпизодах-беседах с Князем 
(первая картина «В поезде», пятая картина «У Рогожина») мелодическая линия вокальной партии Парфена более размеренная, спокойная и приближается к ариозному типу. Оказываясь, по справедливому замечанию исследователя, в «ситуации потаенной любви-ненависти, доставляющей страдания и мучительные переживания героям» (Safronova, 2013: 101-102), Рогожин как бы стихает в своих внешних проявлениях, становится все более задумчивым и словно бы предчувствует неизбежность трагического исхода. Описанное состояние в полной мере отражается в одном из сольных эпизодов, жанр которого обозначим как песня.

В структуре оперы он звучит в завершение девятой, предпоследней картины «Соперницы» (соответствует событиям главы VIII части четвертой романа) и предвосхищает заключительную картину оперы «Примирение», в которой Мышкин и Рогожин сидят у тела мертвой Настасьи Филипповны в доме Парфена (XI глава романа).

Рассматриваемая сцена представляет Рогожина сидящим в кабаке. Такой сцены нет в романе. Она введена в оперу Медведевым. По-видимому, либреттист отталкивался от текста первой части романа, где сам Парфен признается, что, приехав к тетке в Псков, «пошел потом по кабакам на последние, да в бесчувствии всю ночь на улице и провалялся» (Dostoevskij, 1973: 13). Второй раз слово «кабак» звучит в романе из уст Дарьи Алексеевны. Пытаясь урезонить Парфена, разнузданно ведущего себя на праздновании дня рождения Настасьи Филипповны, она строжится: «Ишь, пьяный из кабака, выгнать тебя надо!» (Dostoevskij, 1973: 141). Историки отмечают, что слово «кабак» в России уже со времен Екатерины II имело негативный оттенок и было «базовым» питейным заведением для простого люда, «где никогда не ели» (Dolgih, 2017: 16). Сюда шли, чтобы «залить горе». Возможно, именно этим объяснимо решение создателей оперы разместить героя в кабаке. И вот почему.

Два раздела песни Рогожина становятся своеобразным обрамлением рассказа
Лебедева, благодаря которому зритель узнает о несостоявшейся свадьбе Мышкина и Настасьи Филипповны, о ее побеге из-под венца к Рогожину. Разговорные фразы Лебедева дополняются вокальными репликами Настасьи Филипповны и Мышкина. Либреттист неслучайно поручает пересказ событий Лебедеву. Этот персонаж представлен в романе и опере «господином всезнайкой» и «помимо привычной роли участника событий выступает в опере в качестве резонера, рассказчика» (Voitkevich, 2020: 994).

Для характеристики Рогожина Медведев - исследователь и знаток русского фольклора - выбрал песню «Ах, талан ли мой, талан». Два из множества вариантов ее поэтического текста вошли в I часть «Собрания разных песен» Михаила Дмитриевича Чулкова (1770 год). Однако с напевом поэтический текст впервые был опубликован в 1790 году в знаменитом сборнике Николая Александровича Львова и Иоганна Готфрида Прача «Собрание народных русских песен с их голосами» (рис. 2) в разделе «Протяжные песни».

Анализ доступных нам образцов песни «Ах, талан ли мой, талан» показал, что большинство версий воплощения балладного сюжета этой протяжной песни раскрывают тему «красавица и разбойник». В связи с сюжетной линией романа Рогожин - Настасья Филипповна интересными представляются следующие строки одного из вариантов:

Сокрушила красна девица;

Что ни день, ни ночь покоя нет,

Я не знаю, как разстатися.

Довела она добра молодца

До погибели великия.

Разорился я, добрый молодец,

От души ли красной девицы... (New and completely collection of Russian songs, 1879: 160).

Очевидно, что они напрямую соотносятся с сюжетом произведения и с рассматриваемой оперной ситуацией. Повидимому, все вышесказанное определило выбор либреттистом данного поэтического фольклорного текста. 


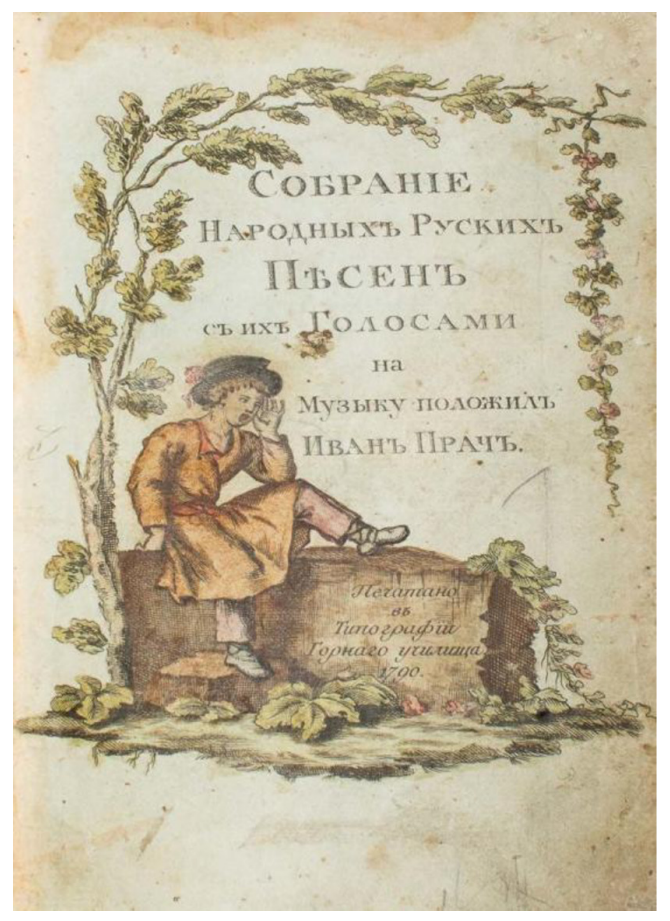

Рис. 2. Титульный лист сборника Н. Львова и И. Прача

Fig. 2. Title page of the collection of N. Lvov and I. Prach

Вместе с тем Медведев изменяет текст первоисточника и привносит в него строки, усиливающие трагическую направленность. Приведем текст Песни, как он представлен в опере, и выделим жирным шрифтом строки, добавленные либреттистом:

Ах, талан ли мой, талан.

Или участь горькая моя,

Иль звезда моя злосчастная

О восьми, восьми концах железных.

Высоко, звезда, ты восходила.

Выше светлого месяца,

Выше красного солнышка

взошла звезда - да пала,

В пепел обратилася, в пепел...

(Vajnberg, 1994: 387-388).

$\cdots$

Ах, талан ли мой, талан.

Разнесчастная судьбинушка,

Черным прахом разлетелася

Черным прахом разлетелася

Поразвеялась, поразвеялась (Weinberg, 1994: 392-393).
Вводимые либреттистом дополнения значительно расширяют семантическое поле цитаты. Фраза «о восьми концах железных» вызывает ассоциации с тюремными кандалами либо октограммой. Она имеет в различных религиях значение духовного восхождения. В православии восьмиконечная звезда символизирует Вифлеем и Богородицу. Однако в тексте песни Рогожина звезда «железная», и она «пала», «в пепел обратилася», «черным прахом разлетелася». Тем самым предвосхищается трагический исход судьбы героя, которого ждет наказание за убийство Настасьи Филипповны и каторга.

Заложенный в тексте фатальный смысл находит воплощение и в мелодии песни Рогожина, созданной Вайнбергом. Композитор руководствуется контекстом сцены и ее положением в опере. Он сохраняет мелодическую напевность и акцентирует черты, свойственные жанру причитаний. Важную роль в напеве играет чистая квинта. Этот интервал можно назвать лейтинтерва- 
лом образной сферы Рогожина. Выскажем предположение, что этот выбор сделан автором музыки не случайно. Имя Парфен, Парфений восходит к древнегреческому слову П $\alpha \rho \theta \dot{\varepsilon} v 10 \varsigma ; ~ « \pi \alpha \rho \theta \dot{\varepsilon} v o \zeta »$ («партенос»), что в переводе означает «целомудренный, девственный, чистый». Однако в данном случае нисходящая мелодическая линия оказывается словно бы замкнута в пределах квинтового интервала. Каждая мелодическая фраза завершается звуком «до», словно символизирует некий роковой предел и неотвратимость «горькой участи» Парфена. Это соответствует слову «талан», которое в словаре Владимира Ивановича Даля обозначено как «рок, судьба, участь» (рис. 3).

Наконец, отметим, что в фольклорной традиции жанр причитаний функционирует в двух обрядовых комплексах: причитания звучат как в свадебном, так и в похоронном ритуалах. Следовательно, выявляемая композитором в интонационном воплощении фольклорного текста семантика жанра причитаний в полной мере соответствует положению рассматриваемой сцены в опере. С одной стороны, здесь совмещаются горькая песня-размышление Рогожина и «анекдот о свадьбе», что позволяет «упорядочить разновременные фрагменты в единую одновременность» и вовлекает цитату «в ассоциативное поле» (Gavrilova, 2020: 1042). С другой - предвосхищается заключительная сцена оперы, в которой «главным действующим лицом является мертвая Настасья Филипповна» (Gozenpud, 1971: 126) - невеста несостоявшейся свадьбы.

\section{Выводы}

Предпринятое исследование показало, что авторы оперы «Идиот» Мечислав Вайнберг и Александр Медведев отражают в сценической драме логику развития и изменения образа Парфена Рогожина. Они следуют за «сценарием» Достоевского и подчеркивают характерные черты героя музыкальными средствами. К ним относятся жанры пляса, оркестровые приемы, использование характерных инструментов, а также введение в вокальную партию фольклорной цитаты старинной русской песни. Сольный номер не только становится отражением внутреннего мира и воспоминаний героя. Он воплощает идею предопределенности трагического завершения романа и оперы. Это позволяет авторам создать необходимую атмосферу и сделать более пронзительным финал музыкальной драмы, в котором два героя сидят подле тела убитой Рогожиным Настасьи Филипповны.
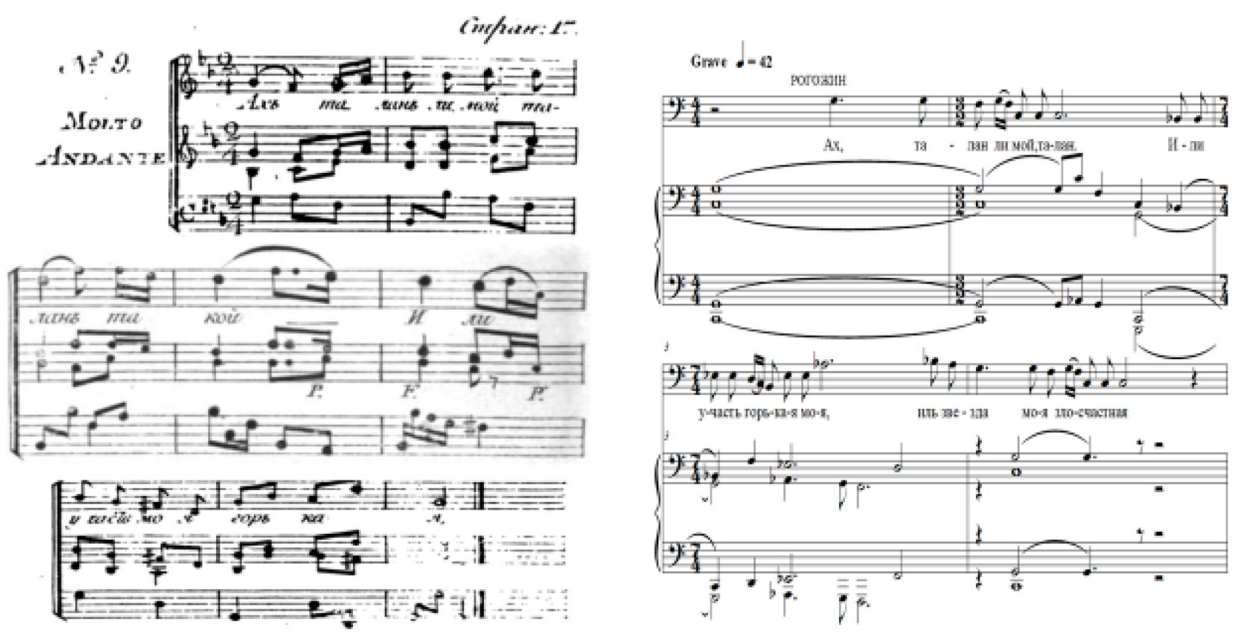

Рис. 3. Песня «Ах, талан ли мой, талан» в сборнике Львова-Прача и в опере М. Вайнберга «Идиот»

Fig. 3. The song «Ah, talan li moi, talan» in the collection of Lviv-Pracha and in the opera by $\mathrm{M}$. Weinberg «Idiot» 


\section{Список литературы / References}

Dolgix E. V. (2017) Pravovoe polozhenie zavedenij obshhestvennogo pitaniya v Rossii 1861-1918 gg. [Legal status of catering establishments in Russia 1861-1918]. Vestnik Moskovskogo universiteta [Moscow University Bulletin]. Seriya 8. Istoriya.. № 5. S. 14-41. (In Russian).

Dostoevskij F. M. (1973) Polnoe sobranie sochinenij v 30 tomax. Tom 8. [Complete set of works in 30 vol. V.8]. L.: Nauka. (In Russian).

Gavrilova, L.V. (2020). «If music is not a memory, then what is it?»: on the modern approach to musical memory in Azio Corghi's creations. J. Sib. Fed. Univ. Humanit. Soc. Sci., 13(6), 1038-1045. DOI: 10.17516/1997-1370-0579. (In English).

Gozenpud A. A. (1971) Dostoevskij i muzy'ka [Dostoevsky and music]. Leningrad: Muzy’ka. (In Russian).

Lobanova E. V. (2016) «Idiot» - neosushhestvlenny'j operny’j zamy'sel N. Ya. Myaskovskogo ['Idiot'. Myaskovsky's unfulfilled operatic plan]. Opera v muzy'kal'nom teatre: istoriya i sovremennost' [Opera in the music theatre: history and modernity]. Sost. I.P. Susidko. Ros.akad.muzy'ki. M.: RAM im. Gnesiny’x, Gos. institut iskusstvoznaniya. S. 127-134. (In Russian).

Novoe i polnoe sobranie rossijskix pesen. Chast' II [New and completely collection of Russian songs. Part II]. Moskva. Universitetskaya tipografiya N. Novikova, 1780. (In Russian).

Safronova E. Yu. (2013) Diskurs prava v tvorchestve F. M. Dostoevskogo 1846-1862 gg. [Discourse of law in the works of F. M. Dostoevsky 1846-1862]. E. Yu. Safronova; pod nauch. red. S. M. Kozlovoj. Barnaul: Izd-vo Alt. un-ta. (In Russian).

Voitkevich S. G. (2020). Peculiarities of adaptation of the novel by F. M. Dostoyevsky «The Idiot» in the opera by M. Weinberg of the same name. J. Sib. Fed. Univ. Humanit. Soc. Sci., 13(6), 989-996. DOI: 10.17516/1997-1370-0622. P. 989-996. (In English).

Weinberg M. S. (1994) Idiot: Opera v 4 d.: Op. 144 / Libr. A. Medvedeva (po odnoim. romanu F. M. Dostoevskogo) [Idiot. The Opera in 4 akts. Libr.by A. Medvedev]. M.: Kompozitor. (In Russian). 